\title{
Comparative study of porous hydroxyapatite/ chitosan and whitlockite/chitosan scaffolds for bone regeneration in calvarial defects
}

This article was published in the following Dove Press journal:

International Journal of Nanomedicine

4 April 2017

Number of times this article has been viewed

\author{
Ding Zhou ${ }^{1, *}$ \\ Chao $\mathrm{Qi}^{2}, *$ \\ Yi-Xuan Chen' \\ Ying-Jie Zhu ${ }^{2}$ \\ Tuan-Wei Sun ${ }^{2}$ \\ Feng Chen ${ }^{2}$ \\ Chang-Qing Zhang'
}

'Department of Orthopedic Surgery, Shanghai Jiao Tong University

Affiliated Sixth People's Hospital,

Shanghai Jiaotong University,

${ }^{2}$ State Key Laboratory of High

Performance Ceramics and Superfine

Microstructure, Shanghai Institute

of Ceramics, Chinese Academy

of Sciences, Shanghai, People's

Republic of China

*These authors contributed equally to this work
Correspondence: Chang-Qing Zhang Department of Orthopedic Surgery, Shanghai Jiao Tong University Affiliated Sixth People's Hospital, 600 Yishan Road, Shanghai 200233, People's Republic of China

Email zhangcq@sjtu.edu.cn

Ying-Jie Zhu

State Key Laboratory of High

Performance Ceramics and Superfine

Microstructure, Shanghai Institute of

Ceramics, Chinese Academy of Sciences,

I 295 Dingxi Road, Shanghai 200050,

People's Republic of China

Email y.j.zhu@mail.sic.ac.cn

\begin{abstract}
Hydroxyapatite $\left(\mathrm{HAP} ; \mathrm{Ca}_{10}\left(\mathrm{PO}_{4}\right)_{6}(\mathrm{OH})_{2}\right)$ and whitlockite $\left(\mathrm{WH} ; \mathrm{Ca}_{18} \mathrm{Mg}_{2}\left(\mathrm{HPO}_{4}\right)_{2}\left(\mathrm{PO}_{4}\right)_{12}\right)$ are widely utilized in bone repair because they are the main components of hard tissues such as bones and teeth. In this paper, we synthesized HAP and WH hollow microspheres by using creatine phosphate disodium salt as an organic phosphorus source in aqueous solution through microwave-assisted hydrothermal method. Then, we prepared HAP/chitosan and WH/chitosan composite membranes to evaluate their biocompatibility in vitro and prepared porous HAP/ chitosan and $\mathrm{WH} /$ chitosan scaffolds by freeze drying to compare their effects on bone regeneration in calvarial defects in a rat model. The experimental results indicated that the $\mathrm{WH} /$ chitosan composite membrane had a better biocompatibility, enhancing proliferation and osteogenic differentiation ability of human mesenchymal stem cells than HAP/chitosan. Moreover, the porous $\mathrm{WH} /$ chitosan scaffold can significantly promote bone regeneration in calvarial defects, and thus it is more promising for applications in tissue engineering such as calvarial repair compared to porous HAP/chitosan scaffold.
\end{abstract}

Keywords: hydroxyapatite, whitlockite, chitosan, osteogenic differentiation, rat critical calvarial defect, tissue engineering

\section{Introduction}

Autogenous bone graft is a commonly used method to repair bone defects, but it is criticized for its donor site morbidity and the bone volume that is harvested is limited. ${ }^{1}$ Therefore, allograft is also often used in clinic as a substitute. ${ }^{2}$ However, allograft also faces risks of recipient rejection and disease transmission. To avoid the disadvantages of tissue-based bone graft, synthetic biocompatible scaffolds have been applied in tissue engineering for bone regeneration. ${ }^{3-5}$

Hydroxyapatite (HAP; $\left.\mathrm{Ca}_{10}\left(\mathrm{PO}_{4}\right)_{6}(\mathrm{OH})_{2}\right)$, a major inorganic component of biological hard tissues such as bone and tooth, has been widely investigated for its application in bone tissue engineering owing to its excellent biocompatibility and biodegradability. ${ }^{6-9}$ For example, Bhumiratana et $\mathrm{al}^{10}$ explored the incorporation of silk sponge matrices with HAP microparticles to generate highly osteogenic composite scaffolds, which could induce in vitro bone formation. HAP embedded in silk sponges significantly enhanced the osteoconductive activity of the scaffolds, indicating that HAP has an outstanding bioactivity and is thus an ideal biomaterial for application in bone tissue engineering.

Whitlockite (WH: $\left.\mathrm{Ca}_{18} \mathrm{Mg}_{2}\left(\mathrm{HPO}_{4}\right)_{2}(\mathrm{PO} 4)_{12}\right)$, a second most abundant mineral in living bone (about $20 \%$ based on the amount of $\mathrm{Mg}^{2+}$ ), is formed by the partial 
substitution of calcium ions with magnesium ions in calcium orthophosphate crystal. ${ }^{11-13}$ Recently, Jang et al ${ }^{14}$ evaluated the bioactive properties of WH nanoparticles through in vitro and in vivo tests and compared the results with those of HAP and $\beta$-tricalcium phosphate $\left(\beta\right.$-TCP; $\left.\beta-\mathrm{Ca}_{3}\left(\mathrm{PO}_{4}\right)_{2}\right)$. Their results indicated that the cellular scaffold fabricated with WH exhibited enhanced differentiation behavior of mouse multipotent cells compared to HAP, and the implants composed of WH enhanced in vivo bone regeneration with intermediate resorbability in comparison with that of HAP and $\beta$-TCP. Therefore, synthetic WH is also an excellent biomaterial with high bioactivity and can be applied in tissue engineering and bone repair.

In this paper, we compared the bone repair performance of porous HAP/chitosan and WH/chitosan scaffolds in calvarial defects. Chitosan, an ideal biomaterial with excellent biocompatibility and antibacterial capability, has been widely applied in tissue engineering and bone repair. ${ }^{15-19}$ Therefore, we chose chitosan as the organic phase to fabricate the inorganic/organic composite porous scaffold for bone regeneration. First, we prepared HAP and WH hollow microspheres by using creatine phosphate (CP) disodium salt as an organic phosphorus source in aqueous solution by microwave-assisted hydrothermal method. Then, we prepared HAP/chitosan and WH/chitosan composite membranes to evaluate their biocompatibility in vitro and prepared porous HAP/chitosan and WH/ chitosan scaffolds by freeze drying to compare their effects on bone regeneration in calvarial defects in a rat model. The experimental results indicated that the WH/chitosan composite membrane had a better biocompatibility, enhancing proliferation and osteogenic differentiation ability of human bone mesenchymal stem cells (hBMSCs) than HAP/chitosan. Moreover, porous WH/chitosan scaffold could significantly promote bone regeneration in calvarial defects; therefore, it is more promising for applications in tissue engineering such as calvarial repair than the porous HAP/chitosan scaffold.

\section{Materials and methods Materials}

Anhydrous calcium chloride $\left(\mathrm{CaCl}_{2}\right)$ and magnesium chloride hexahydrate $\left(\mathrm{MgCl}_{2} \cdot 6 \mathrm{H}_{2} \mathrm{O}\right)$ were purchased from Sinopharm Chemical Reagent Co., Ltd (Beijing, People's Republic of China). CP disodium salt tetrahydrate $\left(\mathrm{C}_{4} \mathrm{H}_{8} \mathrm{~N}_{3} \mathrm{O}_{5} \mathrm{PNa}_{2} \cdot 4 \mathrm{H}_{2} \mathrm{O}\right)$ was purchased from Sangon Biotech (Shanghai, People's Republic of China). Chitosan (viscosity: 200-400 $\mathrm{mPa} \cdot \mathrm{s}$ ) was purchased from Aladdin Chemistry Co., Ltd (Shanghai, People's Republic of China). All reagents were used as received without further purification.

\section{Preparation of the products}

HAP and WH hollow microspheres were synthesized according to our previous reports. ${ }^{12,20}$ For the preparation of HAP hollow microspheres, $0.555 \mathrm{~g}$ of $\mathrm{CaCl}_{2}$ and $0.981 \mathrm{~g}$ of CP were added to $200 \mathrm{~mL}$ of deionized water with magnetic stirring at room temperature. And for the preparation of WH hollow microspheres, $0.389 \mathrm{~g}$ of $\mathrm{CaCl}_{2}, 0.305 \mathrm{~g}$ of $\mathrm{MgCl}_{2} \cdot 6 \mathrm{H}_{2} \mathrm{O}$, and $0.981 \mathrm{~g}$ of $\mathrm{CP}$ were added to $200 \mathrm{~mL}$ of deionized water with magnetic stirring at room temperature. Then, $40 \mathrm{~mL}$ of the resulting clear solution was loaded into a modified polytetrafluoroethylene cylindrical autoclave, sealed, placed in a high-strength outer vessel, heated in a microwave oven (MDS-6; Sineo, Shanghai, People's Republic of China) to the temperature of $120^{\circ} \mathrm{C}$ and maintained at that temperature for $10 \mathrm{~min}$. Microwave oven (frequency $2.45 \mathrm{GHz}$, maximum power $1,000 \mathrm{~W}$ ) is a microwave-hydrothermal synthesis system with a continuous heating mode. The temperature was measured with a platinum resistor temperature sensor (temperature range $0^{\circ} \mathrm{C}-250^{\circ} \mathrm{C}$ ) and controlled by automatic adjustment of the microwave power. The autoclave was in continuous rotation during microwave irradiation to achieve relatively uniform heating. After cooling to room temperature, the product was separated by centrifugation, washed several times with deionized water and ethanol, and then freeze dried.

For the preparation of $\mathrm{HAP} /$ chitosan and $\mathrm{WH} /$ chitosan composite membranes or porous scaffolds, $360 \mathrm{mg}$ of chitosan and $240 \mathrm{mg}$ of HAP or WH hollow microspheres were added to $12 \mathrm{~mL}$ of deionized water. After ultrasonic dispersion for $10 \mathrm{~min}, 12 \mathrm{~mL}$ of acetic acid solution ( 2 vol\%) was added to the mixed solution, and the resulting sol was added to 24 -well culture plates ( $2 \mathrm{~mL}$ per well). Then, the HAP/chitosan and $\mathrm{WH} /$ chitosan composite membranes were formed by drying at $37^{\circ} \mathrm{C}$ for $24 \mathrm{~h}$, and the porous $\mathrm{HAP} /$ chitosan and $\mathrm{WH} /$ chitosan scaffolds were formed by freeze drying.

\section{Characterization}

The as-prepared samples were characterized by X-ray diffraction (XRD) with a X-ray diffractometer (Rigaku D/max $2,550 \mathrm{~V}, \mathrm{Cu} \mathrm{K} \alpha, \lambda=1.54178 \AA$ ) , scanning electron microscope (SEM; Hitachi SU8220 and S-3400N; Hitachi, Tokyo, Japan), and transmission electron microscope (TEM; Hitachi $\mathrm{H}-800$;). $\mathrm{Ca}, \mathrm{Mg}$, and $\mathrm{P}$ contents in the solution were measured using inductively coupled plasma (ICP)-optical emission spectrometer (JY 2000-2; Horiba).

\section{Ion release experiments}

The porous HAP/chitosan or WH/chitosan scaffold (20 mg each) was dispersed in $8 \mathrm{~mL}$ of physiological saline solution 
at $37^{\circ} \mathrm{C}$ with a constant shaking rate $(140 \mathrm{rpm})$. The shaking device was a desk-type constant-temperature oscillator (THI-92A). The supernatant solution (4 mL) was withdrawn for ICP analysis to measure the concentrations of $\mathrm{Ca}, \mathrm{Mg}$, and $\mathrm{P}$ elements at given time intervals, which were replaced with fresh physiological saline of the same volume.

\section{Cell cultures}

The hBMSCs were isolated from human bone marrow during surgery according to the principles of the Helsinki Declaration. Written consents were obtained from each patient suffering from a fracture in proximal femur. All procedures were approved by the Ethical Review Board of Sixth People's Hospital affiliated to Shanghai Jiaotong University. The hBMSCs were purified by centrifuging for $5 \mathrm{~min}$, two times at 1,500 rpm. After discarding the supernatant, the hBMSCs obtained were cultured at $37^{\circ} \mathrm{C}$ in $5 \% \mathrm{CO}_{2}$ incubator in $75 \mathrm{~cm}^{2}$ flasks (Corning Incorporated, Corning, $\mathrm{NY}$, USA) containing $8 \mathrm{~mL}$ of $\alpha$-minimum essential medium ( $\alpha$-MEM; Gibco and Invtrogen, Inc) supplemented with 10\% fetal bovine serum (FBS) (Hyclone, Logan, UT, USA) and $1 \%$ antimicrobial of penicillin and streptomycin (antibioticantimycotic; Hyclone). The culture medium was changed 48 $\mathrm{h}$ after first seeding and then every 3 days until the adherent cells reached $80 \%$ confluence. The cells were subcultured every 3 days and used between passages 3 and 5 .

\section{Cell adhesion and proliferation}

Before hBMSCs were seeded, scaffolds or membranes were sterilized by soaking in $75 \%$ ethanol for $2 \mathrm{~h}$, then rinsed with phosphate-buffered saline (PBS) to eliminate residual ethanol followed by ultraviolet radiation for one night. A total of $2 \times 10^{5} \mathrm{hBMSCs}$ were seeded on scaffolds $(1 \mathrm{~cm}$ in diameter $\times 1 \mathrm{~cm}$ in height) that had been primed with culture medium in 24-well culture plates and incubated in $\alpha$-MEM supplemented with $10 \% \mathrm{FBS}$ at $37^{\circ}$ in a humidified atmosphere of $5 \% \mathrm{CO}_{2}$. After 3 days, the scaffolds were washed three times with PBS and placed for $1 \mathrm{~h}$ in $2.5 \%$ glutaraldehyde in PBS. The fixed samples were washed with PBS and dehydrated in a graded series of ethanol $(30,50,70,90,95$, and $100 \%$ ), followed by soaking in graded series of hexamethyldisilizane for $1 \mathrm{~h}$. The specimens were coated with gold and the morphological characteristics of the attached cells were examined using SEM (Hitachi S-3400N).

The proliferation of the hBMSCs was assessed by cell viability assay (Cell Counting Kit-8 [CCK-8]; Dojindo Molecular Technologies, Inc., Kumamoto, Japan). Briefly, hBMSCs were seeded in 24-well culture plates with wells covered by $\mathrm{HAP} /$ chitosan or $\mathrm{WH} /$ chitosan composite membranes at a concentration of $2 \times 10^{4}$ cells per well and wells without covering as control. After culturing for 1, 3, 5, and 7 days, the culture media were removed and replaced with $360 \mu \mathrm{L}$ of fresh culture medium and $40 \mu \mathrm{L}$ of CCK-8 solution (9:1) and incubated at $37^{\circ} \mathrm{C}$ for $3 \mathrm{~h}$. Then, $100 \mu \mathrm{L}$ of the system was transferred to a 96-well plate for measurement. The absorbance of the samples was measured at $450 \mathrm{~nm}$ with a spectrophotometric microplate reader (Bio-Rad 680; BioRad Laboratories Inc, Hercules, CA, USA). The results were expressed as the optical density of aliquots minus the absorbance of wells without cells. Each sample was assayed in triplicate. The OD values of each sample at $450 \mathrm{~nm}$ were transferred to cell numbers according to a calibration curve of OD value to cell number.

\section{Osteogenic differentiation experiments}

For in vitro osteogenic differentiation experiments, the hBMSCs were trypsinized and seeded in 6-well plates or 24-well plates with or without covering of HAP/chitosan or $\mathrm{WH} /$ chitosan composite membranes and then were cultured in the basic osteogenic differentiation medium ( $\alpha$-MEM, $10 \% \mathrm{FBS}, 50 \mu \mathrm{g} / \mathrm{mL}$ ascorbic acid, $10 \mathrm{mM} \beta$-glycerophosphate, $10^{-7} \mathrm{M}$ dexamethasone, $1 \%$ penicillin-streptomycin), and then incubated at $37^{\circ} \mathrm{C}$ in $5 \% \mathrm{CO}_{2}$ environment. The medium was replaced twice a week, and the osteogenic differentiation was assessed by alkaline phosphatase (ALP) activity assay, quantitative real-time polymerase chain reaction (qRT-PCR), and Western blotting technique.

\section{ALP activity assay}

The osteogenic differentiation of hBMSCs was evaluated by ALP activity assay. After culturing for 7 and 14 days, the cell layers were washed gently with cold PBS and lysed in $200 \mu \mathrm{L}$ of $0.2 \%$ Triton X-100 for $30 \mathrm{~min}$. The lysates were centrifuged at $14,000 \mathrm{rpm}$ for $15 \mathrm{~min}$ at $4^{\circ} \mathrm{C}$ and sonicated. Next, $30 \mu \mathrm{L}$ of the supernatant was mixed with $150 \mu \mathrm{L}$ of the working solution according to the manufacturer's protocol (Nanjing Jiancheng Bioengineering Institute, Nanjing, People's Republic of China). The formation of $p$-nitrophenol from $p$-nitrophenylphosphate, the substrate of ALP, is evaluated by measuring the absorbance at $405 \mathrm{~nm}$ with a microplate reader (Bio-Rad 680; Bio-Rad). The ALP activity was calculated by the ratio of experimental samples to standard and was expressed by millimoles of $p$-nitrophenol produced per minute per milligram of protein.

\section{Quantitative real-time polymerase chain reaction}

The expression levels of osteogenesis-related genes including $A L P$, runt-related transcription factor 2 (Runx2), osteocalcin 
$(O C N)$, and type I collagen ( $C O L-1)$ were measured using qRTPCR. The total RNA was extracted from the hBMSCs after culturing for 7 days by TRIzol reagent (Life Technologies) and RNA Kit (TransGen Biotech, Beijing, People's Republic of China). Then TakaRa Prime-Script 1st strand cDNA Synthesis Kit (6110A) was used for cDNA synthesis. Complementary DNA was synthesized using $1 \mu \mathrm{g}$ RNA following the manufacturer's instructions. The qRT-PCR analysis was performed using ABI Prism 7900HT Thermal Cycler (Applied Biosystems Pty Ltd, Scoresby, VIC, Australia) using SYBR Green detection reagent. The relative expression of the genes was normalized against the housekeeping gene $\beta$-actin. The primer sequences for the target genes are listed in Table 1. All samples were measured in triplicate.

\section{Western blotting analysis}

The hBMSCs on the membranes and in the control were lysed after osteogenic differentiation for 7 days with Cell Lytic buffer for $30 \mathrm{~min}$. These lysates were sonicated for $10 \mathrm{~s}$ and centrifuged at $14,000 \mathrm{rpm}$ for $15 \mathrm{~min}$ at $4^{\circ} \mathrm{C}$. The protein concentrations were determined using a BCA protein assay kit (Roche, Rockford, IL, USA). Equal amounts of the lysates were loaded onto a 5\% stacking and 10\% resolving SDS-PAGE gel. After electrophoresis, the proteins were transferred to PVDF (polyvinylidene fluoride) membranes and reacted with Runx2 (1:1,000, Abcam) antibody. For measurement, horseradish peroxidase-conjugated secondary antibodies (1:1,000; Jackson ImmunoRes, West Grove, PA, USA) were used, followed by enhanced chemiluminescence (ECL) Plus Western Blotting Detection System (GE Healthcare UK Ltd, Little Chalfont, UK). The immunoreactive bands formed were quantified by scanning densitometry software (ImageJ; National Institutes of Health, Bethesda, MD, USA). Protein expression levels were normalized to those of a housekeeping gene, $\beta$-actin (1:1,000 dilution with 1\% bovine serum albumin in 0.01 M PBS; Santa Cruz Biotechnology Inc., Dallas, TX, USA). All Western blotting analyses were repeated three times under the same conditions.

\section{Animal and surgical procedure}

All animal experiments in this study followed the guidelines of Animal Welfare Act and were approved by the Animal Care and Use committee of Shanghai Sixth People's Hospital, Shanghai Jiaotong University School of Medicine. Thirty male Sprague-Dawley rats (12 weeks; body weight 250-300 g) were used in the experiments. WH/chitosan and HAP/chitosan porous scaffold were selected as experimental groups while vacant defect was selected as negative control group. The porous scaffolds were cut into a disk with a diameter of $5 \mathrm{~mm}$ and a thickness of 1.5-2 $\mathrm{mm}$. After anesthetization with intraperitoneal injection of $4 \%$ chloral hydrate $(0.9 \mathrm{~mL} / 100 \mathrm{~g})$, we made a sagittal incision $(1.0-1.5 \mathrm{~cm})$ on the scalp and blunt dissection to expose the calvarium. Then, a full-thickness defect with a diameter of $5 \mathrm{~mm}$ was made by using electric trephine under constant irrigation with $0.9 \%$ saline. The bone defects were divided into three groups and randomly filled with $\mathrm{WH} /$ chitosan porous scaffold $(n=12)$ or HAP/chitosan porous scaffold $(n=12)$, or left empty $(n=6)$ (negative control). The cuts were closed layer by layer with 4-0 silk sutures. Each animal received an intramuscular injection of antibiotics postsurgery. All animals received standardized diet and were monitored daily for potential complications or abnormal behavior.

\section{Sequential fluorescent labeling}

Fluorochrome labeling is a widely used standard technique for investigating the dynamics of bone formation. The fluorochrome labels can bind to calcium ions in blood and be incorporated at sites of mineralization front at the time of administration. The distance between the stained fronts is regarded as the bone formation at a specific time interval. ${ }^{21}$ A polychrome sequential fluorescent labeling was performed on rats sacrificed at 8 weeks to observe the extent of new bone formation and mineralization. At 2, 4, and 6 weeks postsurgery, the animals were subjected to an intraperitoneal injection of fluorochromes with $25 \mathrm{mg} / \mathrm{kg}$ tetracycline

Table I Primers for qRT-PCR

\begin{tabular}{lll}
\hline Target genes & $\begin{array}{l}\text { Forward primer } \\
\text { sequence } \mathbf{( 5}^{\prime} \mathbf{- 3}^{\prime} \mathbf{)}\end{array}$ & $\begin{array}{l}\text { Reverse primer } \\
\text { sequence }\left(\mathbf{5}^{\prime} \mathbf{-} \mathbf{3}^{\prime}\right)\end{array}$ \\
\hline ALP & ACCACCACGAGAGTGAACCA & CGTTGTCTGAGTACCAGTCCC \\
Runx2 & CCAACCCACGAATGCACTATC & TAGTGAGTGGTGGCGGACATAC \\
OCN & CCCCCTCTAGCCTAGGACC & ACCAGGTAATGCCAGTTTGC \\
COL-I & CAGCCGCTTCACCTACAGC & TTTTGTATTCAATCACTGTCTTGCC \\
$\beta$-actin & TTCAACACCCCAGCCATGT & GTGGTACGACCAGAGGCATACA \\
\hline
\end{tabular}


(Sigma-Aldrich Co., St Louis, MO, USA), $30 \mathrm{mg} / \mathrm{kg}$ alizarin red (Sigma), and $20 \mathrm{mg} / \mathrm{kg}$ calcein (Sigma-Aldrich).

\section{Microcomputed tomography (micro-CT)}

The rat calvaria in all groups were harvested at 8 weeks postsurgery and subjected to micro-CT scan (Skyscan 1176, Kontich, Belgium). Scanning was performed at resolutions of $9 \mu \mathrm{m}$ for the undecalcified samples. The following experimental settings were used: an X-ray voltage of $65 \mathrm{kV}$, an anode current of $278 \mu \mathrm{A}$, and an exposure time of $520 \mathrm{~ms}$ for each of the 180 rotational steps. Two-dimensional (2D) images were acquired first with which three-dimensional (3D) images were reconstructed and then the local bone mineral density (BMD) and bone volume to total bone volume (BV/TV) were quantified in the reconstructed 3D micro-CT images.

\section{Histology}

After dehydrating in a graded series of ethanol (75\%-100\%) and embedding in methyl methacrylate, $150 \mu \mathrm{m}$ thick sections of undecalcified samples were made along the coronal surface using a microtome (Leica, Hamburg, Germany). The sections were observed for fluorescent labeling using a confocal laser scanning microscope (Leica). The excitation/emission wavelengths of the chelating fluorochromes used were 405/560-590 nm (tetracycline, yellow), 543/580-670 nm (alizarin red, red), and 488/500-550 nm (calcein, green). The coronal sections were then polished to a thickness of $40 \mu \mathrm{m}$ and stained by Van Gieson's picrofuchsin technique to identify new bone (red area) in the scaffold.

After decalcification and paraffin embedding, samples were sectioned at a thickness of $5 \mu \mathrm{m}$ in the coronal plane. The new bone structures were stained by hematoxylin and eosin (H\&E). For immunohistochemical staining, the sections were deparaffinized and processed with antigen retrieval, incubated with anti-OCN (Abcam) primary antibody, and then with biotinlabeled secondary antibody. After reaction with DAB (3,3'diaminobenzidine tetrahydrochloride; $\mathrm{MW}=214.1$ ) substrate and counterstaining, the positive area of OCN deposition was observed by a light microscope (LEICA DM 4000).

\section{Statistical analysis}

All the experiments were performed in triplicate unless otherwise specified. The data were expressed as mean \pm standard deviation (SD). $t$-test and one-way analysis of variance by Student-Newman-Keuls post-hoc tests were used to determine the level of significance, with $P$-values less than 0.05 being considered significant.

\section{Results Formation and characterization of the products}

The powder samples synthesized using CP disodium salt as an organic phosphorus source in aqueous solution were characterized by XRD, SEM, TEM, and dynamic light scattering (DLS). As shown in Figure 1A and E, the XRD patterns indicate that the samples prepared by microwave-assisted hydrothermal method at $120^{\circ} \mathrm{C}$ for $10 \mathrm{~min}$ can be indexed to a single phase of HAP (JCPDS 09-0432) and WH (JCPDS 09-0169), respectively. Moreover, the HAP sample consisted of HAP nanosheet/nanorod-assembled porous hollow microspheres (Figure 1B and C), while the WH sample consisted of WH nanoparticle-assembled hollow porous microspheres (Figure $1 \mathrm{~F}$ and $\mathrm{G}$ ). The selected-area electron diffraction patterns (insets of Figure 1C and $\mathrm{G}$ ) indicate that the HAP and $\mathrm{WH}$ porous hollow microspheres have a good crystallinity. The diameters of both HAP and WH porous hollow microspheres were about $1 \mu \mathrm{m}$ (Figure 1D and H).

In order to utilize the as-prepared HAP and WH porous hollow microspheres in tissue engineering and bone repair, chitosan was chosen as the organic phase to fabricate the inorganic/organic complex scaffold. To evaluate the biocompatibility and osteogenic differentiation ability, we prepared $\mathrm{HAP} /$ chitosan and $\mathrm{WH} /$ chitosan composite membranes (Figure 2) through drying at $37^{\circ} \mathrm{C}$ for $24 \mathrm{~h}$. To apply HAP/ chitosan and $\mathrm{WH} /$ chitosan complex in the bone regeneration of calvarial defects, we prepared porous HAP/chitosan and WH/chitosan scaffolds (Figure 3) by freeze drying. As shown in Figure 3, the HAP/chitosan and WH/chitosan scaffolds consisted of porous structure with an average pore size of about $105 \mu \mathrm{m}$ which is beneficial to help the cells settle inside the scaffolds. ${ }^{22}$ Moreover, the wall of pores was composed of $\mathrm{HAP} /$ chitosan or $\mathrm{WH} /$ chitosan, and the as-prepared HAP and $\mathrm{WH}$ porous hollow microspheres were evenly dispersed in the chitosan organic phase (Figure $3 \mathrm{C}$ and $\mathrm{G}$ ).

Furthermore, we investigated the degradation properties of the as-prepared porous $\mathrm{HAP} /$ chitosan and $\mathrm{WH} /$ chitosan scaffolds because their stability is a key element affecting osteogenesis in vivo. After the porous HAP/chitosan and $\mathrm{WH} /$ chitosan scaffolds were immersed in physiological saline at different times, the amounts of HAP and WH dissolved were calculated according to the $\mathrm{Ca}^{2+}$ ions released into the physiological saline and measured by ICP analysis. As shown in Figure 4A, the amounts of HAP and WH dissolved from the HAP/chitosan and $\mathrm{WH} /$ chitosan scaffolds increased with time and reached $487 \mu \mathrm{g}$ and $326 \mu \mathrm{g}$, 


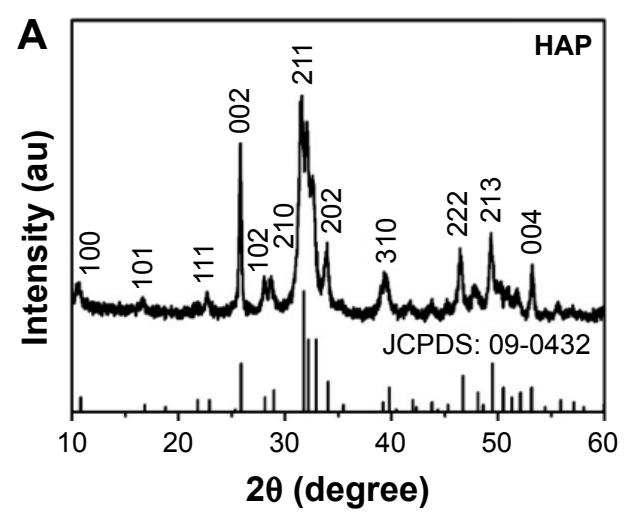

C

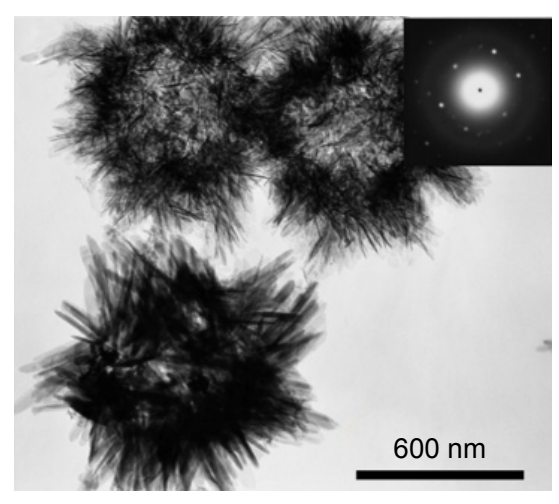

\section{$\mathrm{E}$}

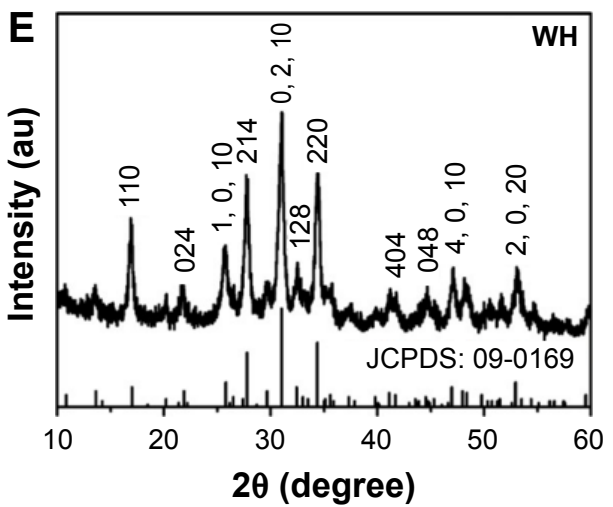

G

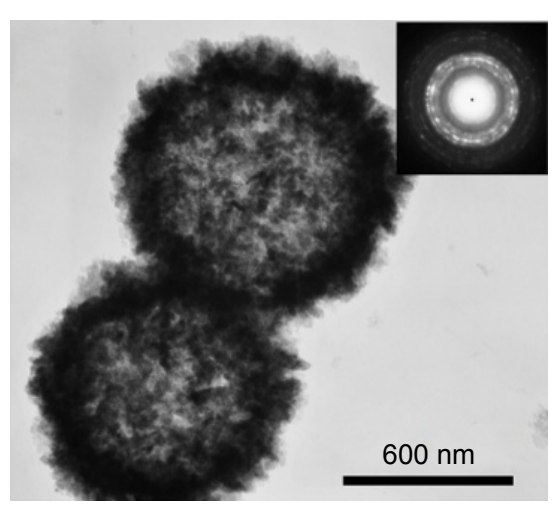

B
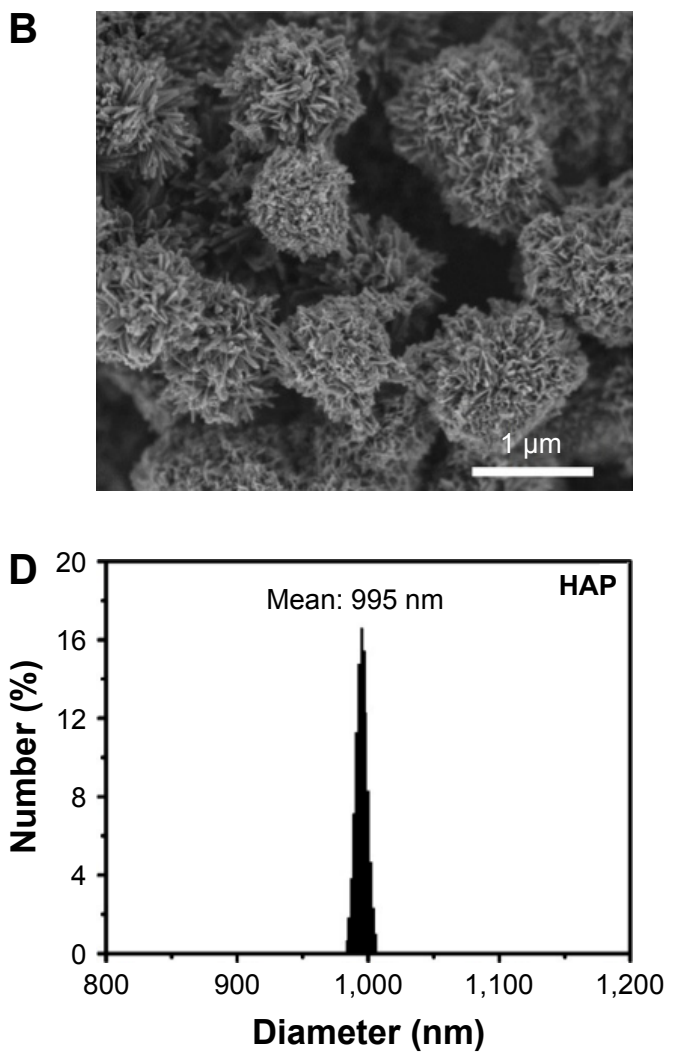

$\mathbf{F}$
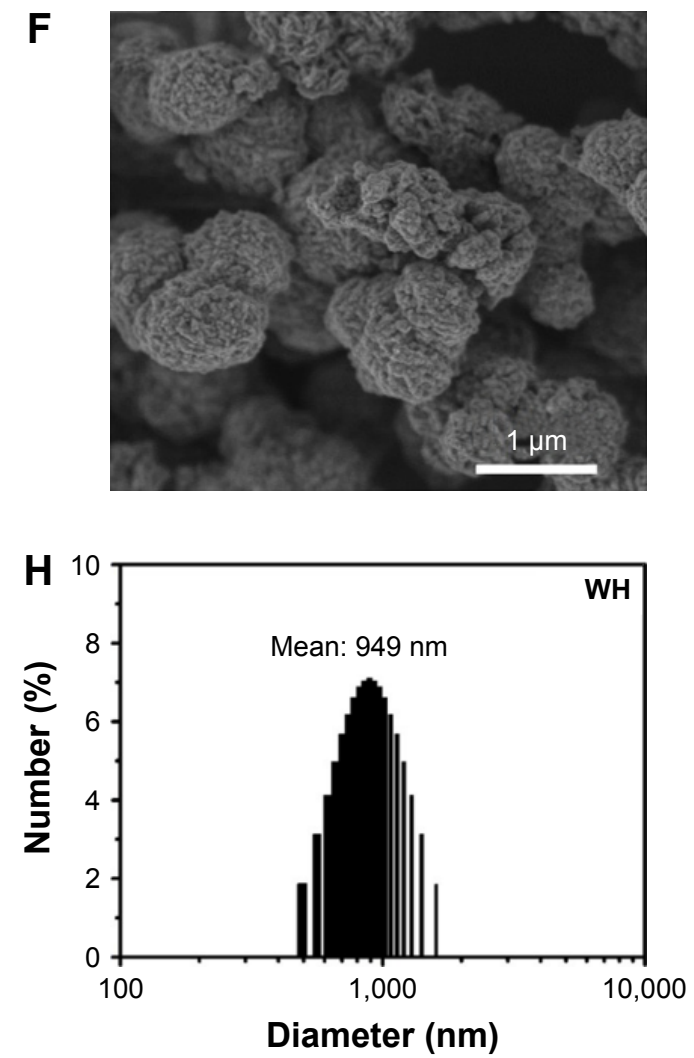

Figure I XRD patterns (A and E), SEM micrographs (B and F), TEM micrographs (C and $\mathbf{G})$ and DLS size distributions (D and $\mathbf{H})$ of HAP (A-D) and WH (E-H) porous hollow microspheres that were prepared by using creatine phosphate disodium salt as an organic phosphorus source through the microwave-assisted hydrothermal method at $120^{\circ} \mathrm{C}$ for $10 \mathrm{~min}$. Insets of $(\mathbf{C})$ and $(\mathbf{G})$ are selected-area electron diffraction patterns.

Abbreviations: XRD, X-ray diffraction; SEM, scanning electron microscope; TEM, transmission electron microscopy; DLS, dynamic light scattering; WH, whitlockite; HAP, hydroxyapatite. 

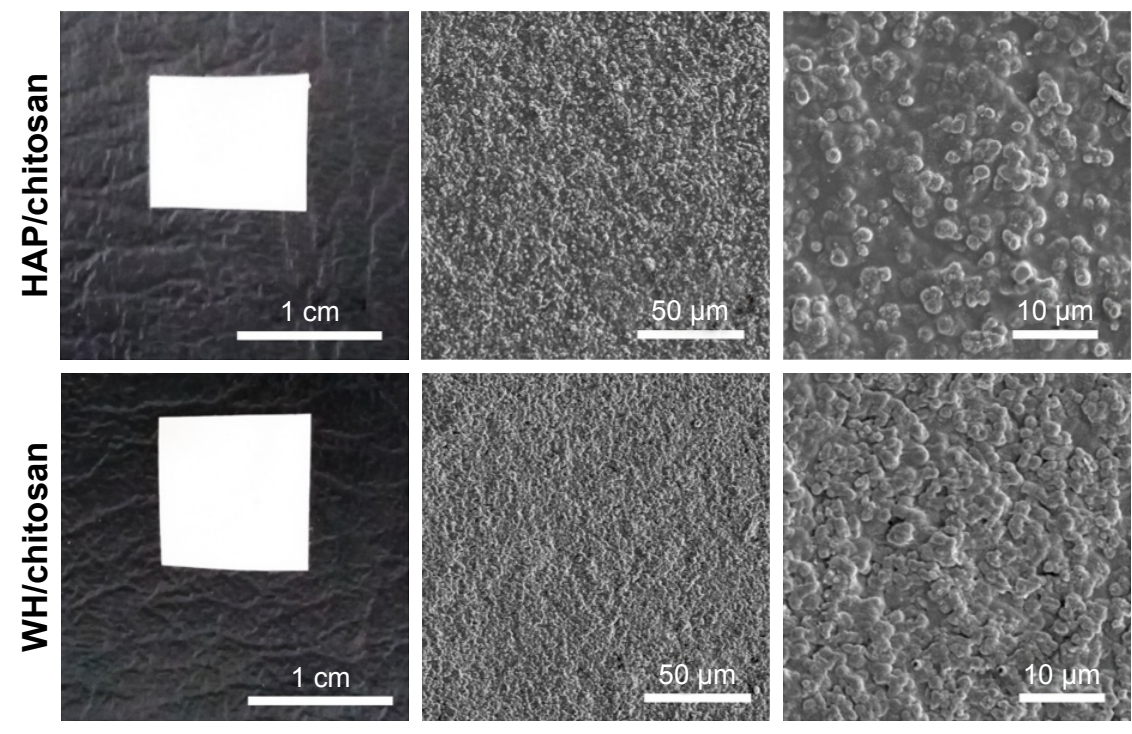

Figure 2 Optical photographs (first column) and SEM micrographs (middle and last columns) of the HAP/chitosan (top row) and WH/chitosan (bottom row) composite membranes prepared by drying at $37^{\circ} \mathrm{C}$ for $24 \mathrm{~h}$.

Abbreviations: SEM, scanning electron microscope; $\mathrm{WH}$, whitlockite; HAP, hydroxyapatite.

respectively, at 28 days. Thus, the dissolution of HAP in the $\mathrm{HAP} /$ chitosan scaffold is faster than that of WH in the WH/ chitosan scaffold, indicating that HAP/chitosan scaffold is less stable than the $\mathrm{WH} /$ chitosan scaffold. In addition, $\mathrm{Mg}$ element was gradually released from the $\mathrm{WH} /$ chitosan scaffold (Figure 4B).

\section{Cell adhesion and proliferation assay}

The cell adhesion of hBMSCs on the surface of porous HAP/ chitosan and $\mathrm{WH} /$ chitosan scaffolds after culturing for 3 days was observed by SEM micrographs. As shown in Figure 5, the hBMSCs attached well and spread on the surface of both groups, exhibiting a regular phenotype of hBMSCs.

The cell proliferation of hBMSCs was determined using CCK-8 assay and the results are shown in Figure 6. The number of hBMSCs that were transferred by the calibration curve (data not shown) reflects that the cell increased in a time-dependent manner. When the hBMSCs were cultured for 3, 5, and 7 days, the cells on $\mathrm{WH} /$ chitosan membranes significantly outnumbered those on HAP/chitosan membranes. Besides, cells on WH/chitosan or HAP/chitosan membranes were significantly more than the control, indicating greatest proliferation of hBMSCs cultured on $\mathrm{WH} /$ chitosan membranes and better biocompatibility of both $\mathrm{WH} /$ chitosan and $\mathrm{HAP} /$ chitosan membranes than the control.

\section{ALP activity assay}

ALP is a hydrolase enzyme that is elevated in the procedure of osteoblast differentiation before maturation. ${ }^{23}$ Therefore, we measured the ALP activity of hBMSCs after being cultured on $\mathrm{WH} /$ chitosan and HAP/chitosan membranes at days 7 and 14 . The results were calculated by normalizing to protein contents. As shown in Figure 7, hBMSCs cultured on WH/chitosan membranes displayed significantly higher ALP activity throughout the observation period in comparison with those of HAP/chitosan membranes in both time points. This observation showed that the $\mathrm{WH} /$ chitosan membranes had greater osteogenic effect on hBMSCs than $\mathrm{HAP} /$ chitosan membranes, which was in accordance to the results obtained by Western blot and PCR.

\section{Gene expression}

Gene expressions including collagen 1, ALP, Runx2, and $O C N$ of hBMSCs after being cultured on $\mathrm{WH} /$ chitosan and $\mathrm{HAP} /$ chitosan membranes for 7 days were determined using real-time PCR assays, and the results are shown in Figure 8. hBMSCs cultured on $\mathrm{WH} /$ chitosan membranes exhibited significantly higher expression level of these four genes compared to those on HAP/chitosan membranes.

\section{Protein expression}

As shown in Figure 9, Western blot analysis demonstrated that Runx2 expression in hBMSCs significantly increased after the cells were seeded on the WH/chitosan membranes for 7 days compared to HAP/chitosan group or the control. Besides, HAP/chitosan group showed higher Runx2 expression than the control. Runx2 plays an essential role in the differentiation of immature osteoblast and is regarded as an early marker of osteoblast. ${ }^{24}$ In this study, we found that 

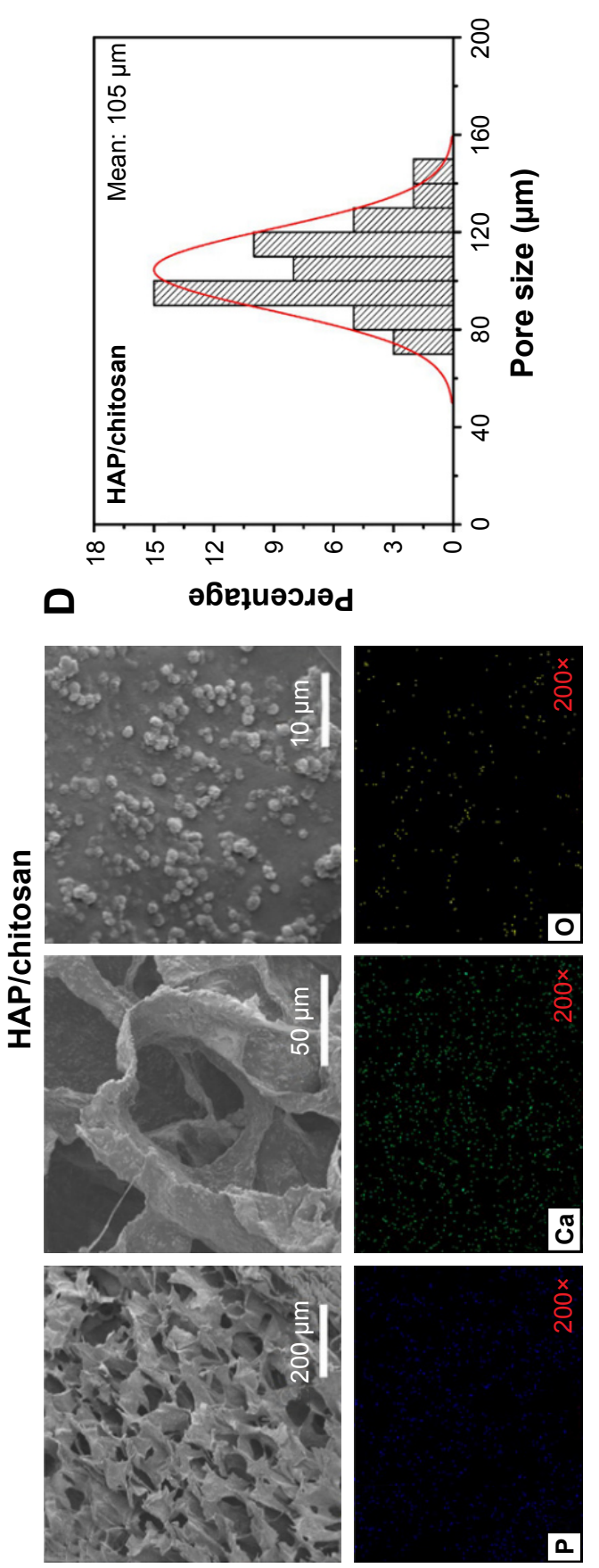

$\boldsymbol{m}$

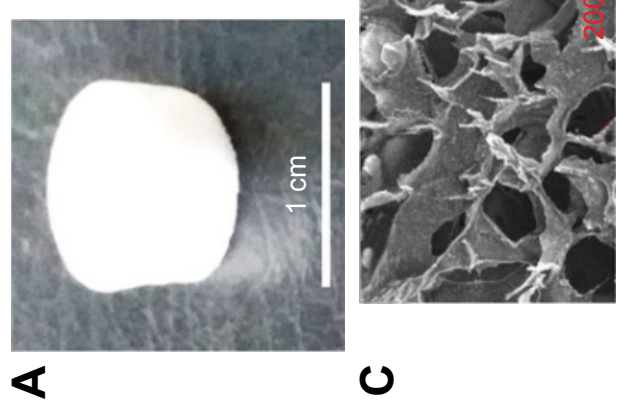

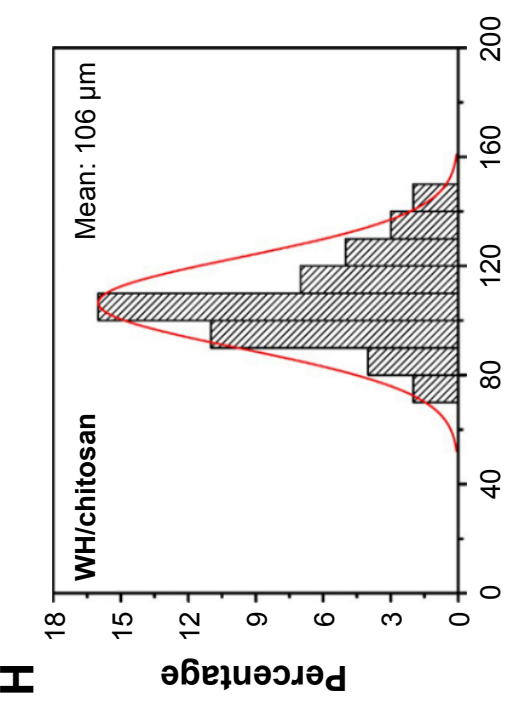
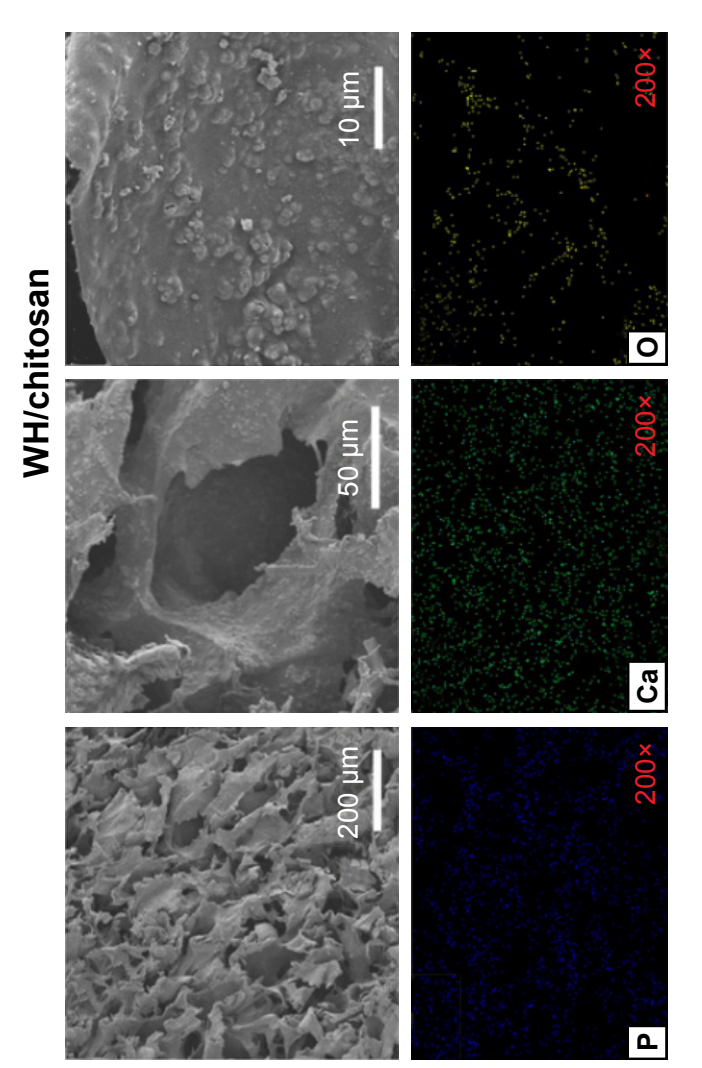

ᄂ

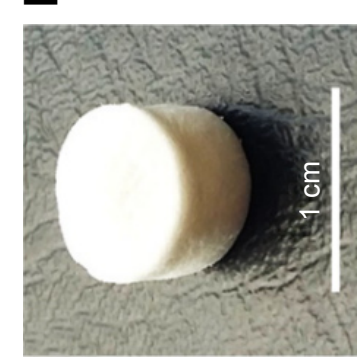

ш

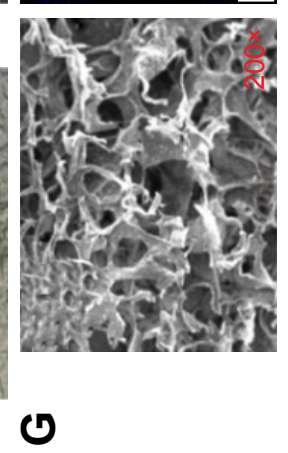

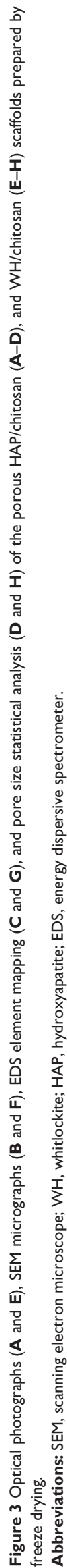



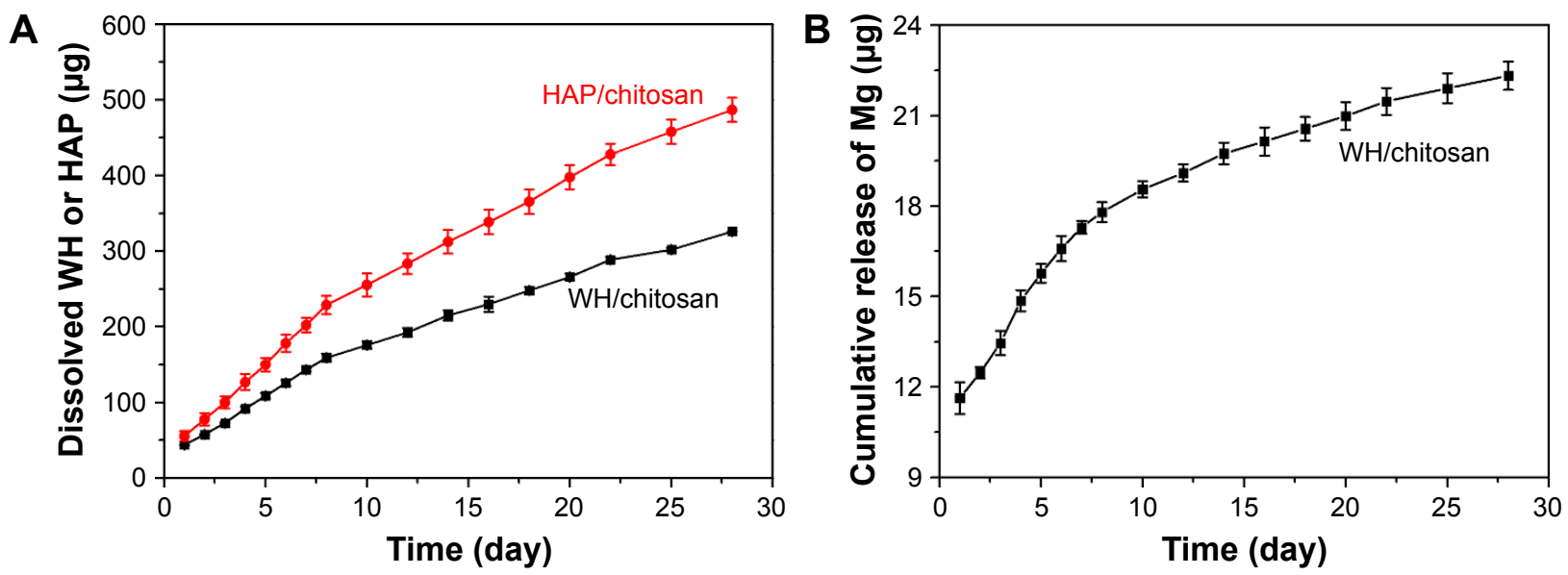

Figure 4 The amounts of HAP and WH dissolved $(\mathbf{A})$ and the cumulative release amount of $\mathrm{Mg}(\mathbf{B})$ from porous HAP/chitosan and WH/chitosan scaffolds after being immersed in physiological saline at different times. The amounts of HAP and WH were calculated according to the $\mathrm{Ca}^{2+}$ ions released into the physiological saline and measured by ICP analysis. No Mg release could be detected from HAP/chitosan.

Abbreviations: $\mathrm{WH}$, whitlockite; HAP, hydroxyapatite; ICP, inductively coupled plasma.

WH/chitosan significantly increased Runx2 expression in hBMSCs after osteogenic culture for 7 days, which is similar to the results of osteogenic gene expression.

\section{Evaluation of osteogenesis in vivo}

Reconstructed 3D and 2D micro-CT images of rat calvarial defects implanted for 8 weeks with the HAP/chitosan and WH/chitosan scaffolds are shown in Figure 10. The images show a higher number of new bone in the defects implanted with $\mathrm{WH} /$ chitosan scaffolds than the $\mathrm{HAP} /$ chitosan group. The defects implanted with the HAP/chitosan scaffolds showed obvious gaps between the scaffolds and bone around the defects, while $\mathrm{WH} /$ chitosan exhibited closer attachment to the host bone. Quantitative analysis of micro-CT images indicated that the BMD in the $\mathrm{WH} /$ chitosan scaffolds was significantly higher than that in the HAP/chitosan scaffolds. The BV/TV determined by the micro-CT images showed a trend similar to BMD. Together, these results suggested that the $\mathrm{WH} /$ chitosan scaffolds had a greater ability to integrate with the host bone and promote bone growth than
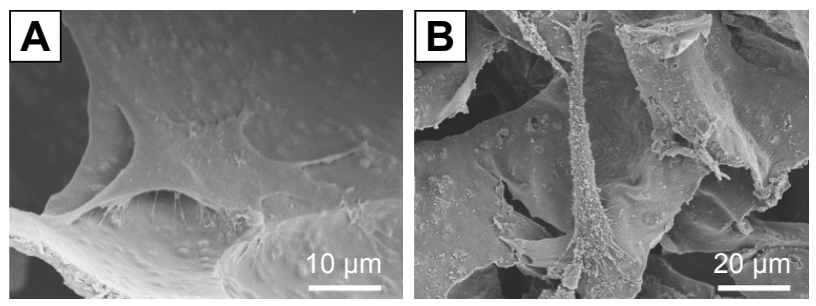

Figure 5 SEM images of hBMSCs on the surface of HAP/chitosan (A) and WH/ chitosan (B) scaffolds after culturing for 3 days.

Abbreviations: $\mathrm{WH}$, whitlockite; HAP, hydroxyapatite; SEM, scanning electron microscope; hBMSCs, human mesenchymal stem cells. the HAP/chitosan scaffolds. New bone formation appeared not only on the surface of $\mathrm{WH} /$ chitosan scaffold but also into the scaffold.

Investigation into sections of scaffolds in both groups, as Figure 11 shows, exhibited the ingrowth condition of new bone and mineralization. On one hand, fluorochrome-labeling analysis showed a motion of bone formation. After 2 weeks, tetracycline (yellow) deposited onto $\mathrm{WH} /$ chitosan implants in broader area than HAP/chitosan, exhibiting more intense and extensive yellow fluorescence. Furthermore, alizarin red (4 weeks) can be barely found in HAP/chitosan group, while a little but more than in HAP/chitosan can be found

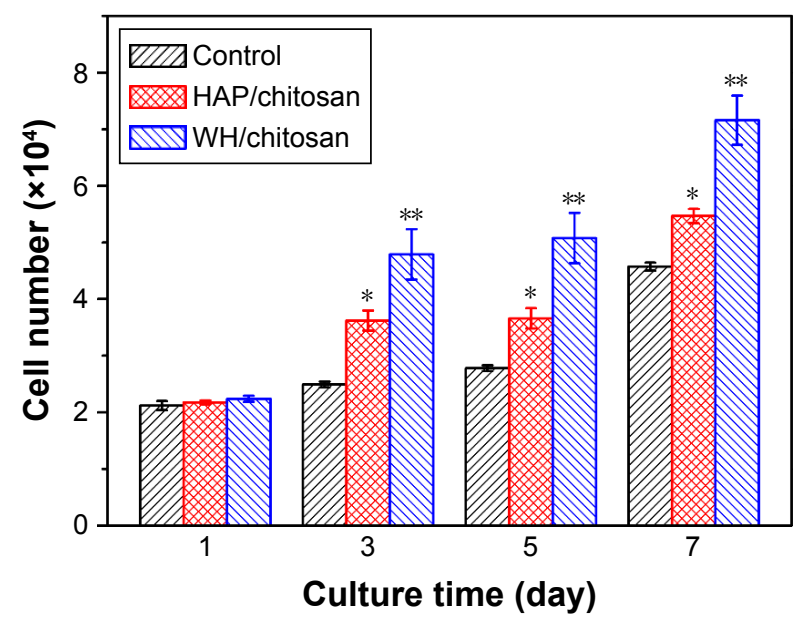

Figure 6 Cell proliferation of hBMSCs cultured on HAP/chitosan and WH/chitosan membranes and in control membrane at different times. Data are expressed as mean $\pm \mathrm{SD}$. *Significant difference between HAP/chitosan and control $(P<0.05)$; **significant difference between $\mathrm{WH} /$ chitosan and $\mathrm{HAP} /$ chitosan or the control $(P<0.05)$.

Abbreviations: $\mathrm{WH}$, whitlockite; HAP, hydroxyapatite; SD, standard deviation; hBMSCs, human mesenchymal stem cells. 


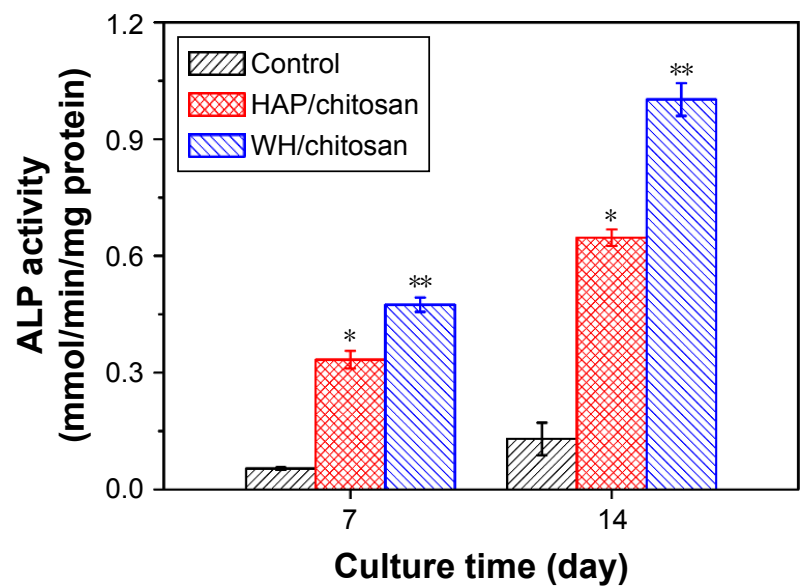

Figure 7 Quantitative ALP activity of hBMSCs cultured on WH/chitosan and HAP/chitosan membranes for 7 and 14 days. Data are expressed as mean \pm SD. *Significant difference between HAP/chitosan and control $(P<0.05)$; **significant difference between $\mathrm{WH} /$ chitosan and HAP/chitosan or the control $(P<0.05)$.

Abbreviations: ALP, alkaline phosphatase; $\mathrm{WH}$, whitlockite; HAP, hydroxyapatite; $\mathrm{SD}$, standard deviation; hBMSCs, human mesenchymal stem cells.

in $\mathrm{WH} /$ chitosan, indicating a larger bone formation rate in $\mathrm{WH} /$ chitosan group. At a later time point (6 weeks), calcein (green) absorbed into the bone area manifested more intensity and extensity in $\mathrm{WH} /$ chitosan group than in $\mathrm{HAP} /$ chitosan, to the same extent as tetracycline deposited at 2 weeks, indicating that this bone formation in this area has been accomplished as early as 4 weeks before. On the other hand, Van Gieson's picrofuchsin confirmed the ingrowth condition because only the collagen in bone could be colored. To be specific, WH/chitosan group exhibited stronger colored area than the HAP/chitosan group. According to the set of images collected at different times points, the newly formed bone

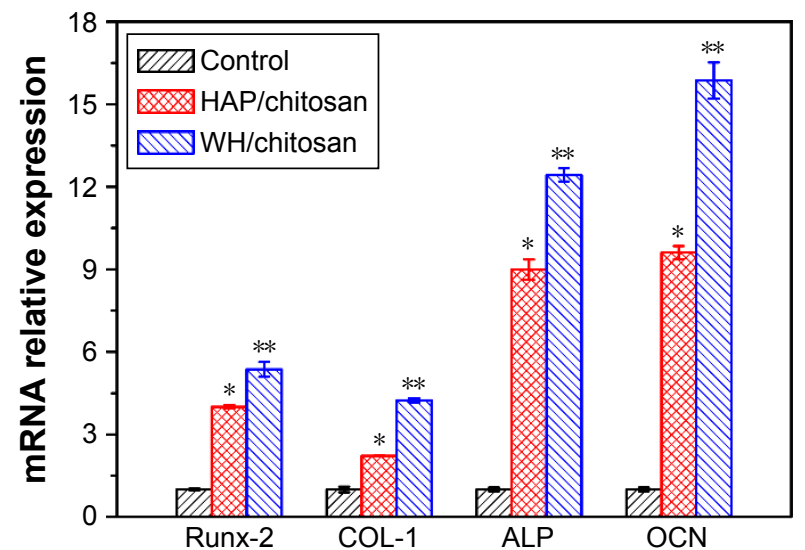

Figure 8 Osteogenic gene expression of collagen I, ALP, Runx2, and OCN after hBMSCs were cultured on WH/chitosan and HAP/chitosan membranes for 7 days. Data are expressed as mean \pm SD. *Significant difference between HAP/chitosan and control $(P<0.05)$; **significant difference between $\mathrm{WH} /$ chitosan and $\mathrm{HAP} /$ chitosan or the control $(P<0.05)$.

Abbreviations: $A L P$, alkaline phosphatase; $\mathrm{WH}$, whitlockite; HAP, hydroxyapatite; SD, standard deviation; hBMSCs, human mesenchymal stem cells; OCN, osteocalcin.

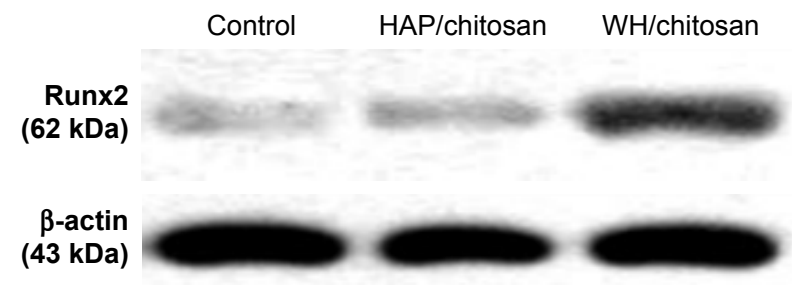

Figure 9 Western blot analysis of protein expression of Runx2 in hBMSCs cultured on the control, $\mathrm{WH} /$ chitosan, and HAP/chitosan membranes for 7 days.

Abbreviations: WH, whitlockite; HAP, hydroxyapatite; hBMSCs, human mesenchymal stem cells.

vertically spread in the implants, and the most distinctive fluorescent lines were produced by $\mathrm{WH} /$ chitosan, which can be seen by Van Gieson's picrofuchsin as well.

A higher number of new bone tissue were found in defects implanted with the WH/chitosan scaffolds than with the HAP/ chitosan scaffolds at 8 weeks, which is shown in the images of decalcified sections stained with H\&E staining (Figure 12). OCN is a protein secreted from only mature osteoblasts. ${ }^{25}$ We can see that the OCN distributed around the newly formed bone and more positive area of OCN was present in $\mathrm{WH} /$ chitosan scaffolds. The histomorphometric results showed that the $\mathrm{WH} /$ chitosan scaffolds had significantly better capacity to heal rat calvarial defects in comparison with HAP/chitosan scaffolds.

\section{Discussion}

The ability to promote osteogenesis is critical for synthetic biomaterials to be applied in healing bone defects. As a major component of regular bone, HAP is osteoconductive and not osteoinductive. ${ }^{26}$ HAP can support bone formation from marrow cells but not promote bone formation. WH is a kind of calcium phosphate existing in natural bone tissue and contains $\mathrm{Mg} .{ }^{27} \mathrm{As}$ it is difficult to be detected and unstable, WH is hard to be separated from bone tissue and synthesized. ${ }^{13}$ Therefore, we used CP disodium salt as an organic phosphorus source in aqueous solution to form WH through microwave-assisted hydrothermal method. The WH prepared consisted of nanoparticle-assembled hollow porous microspheres with a diameter of $1 \mu \mathrm{m}$.

Several studies have reported that WH promotes osteogenesis. Jang et al found that WH pellets could promote proliferation and osteogenic differentiation in osteoblasts. Also, they found that WH particles supported new bone formation in calvaria defects in rats, with higher BS/TV compared to HAP, indicating that more newly formed bones were found in WH. ${ }^{14,28}$ However, given that the scaffold can be more applicable in clinical use for its good fixation into a regional 

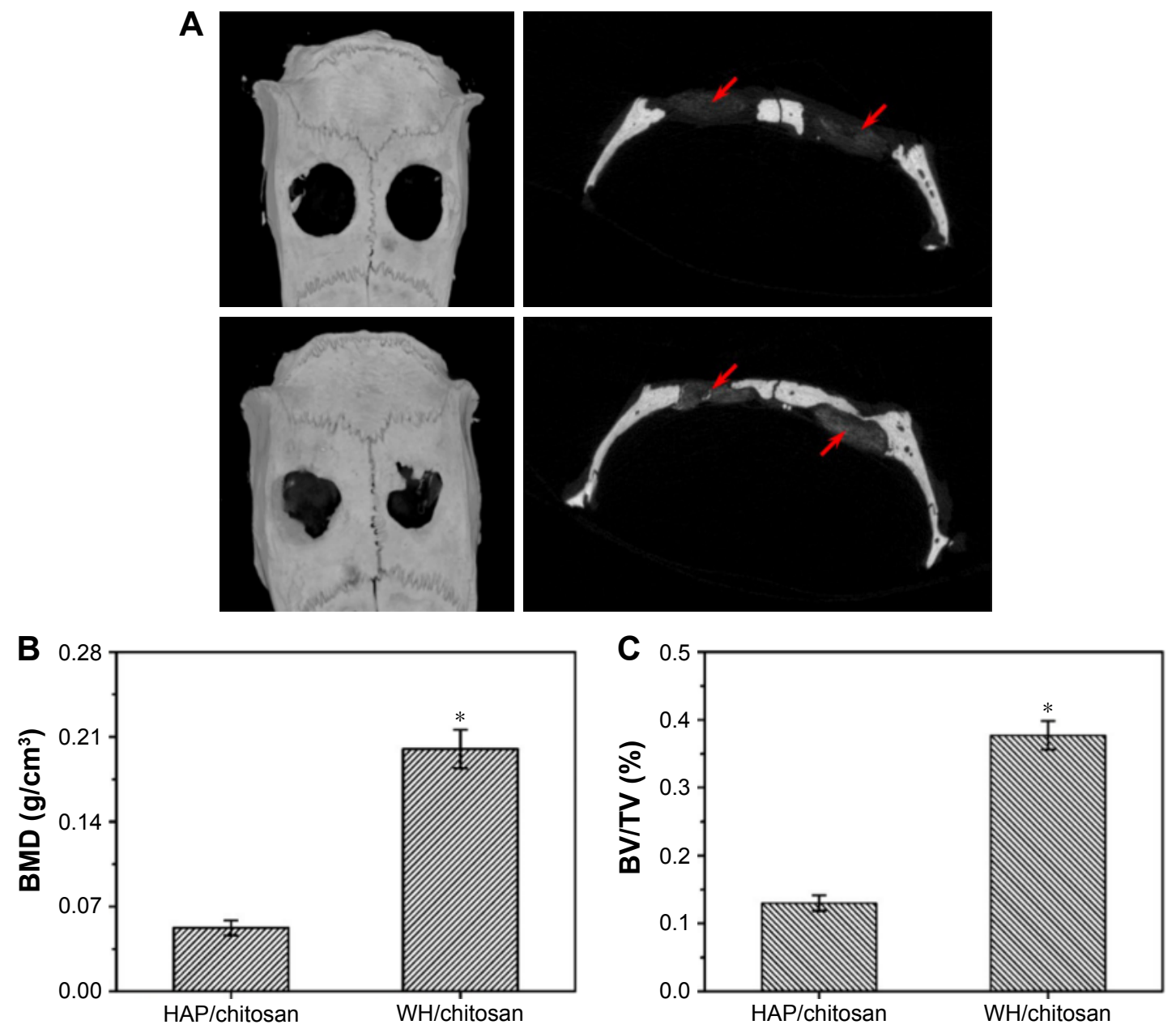

Figure 10 Micro-CT measurement of bone formation in the rat calvarial defects implanted with HAP/chitosan and WH/chitosan scaffold at 8 weeks after implantation. (A) Top and cross-sectional views of reconstructed images; red arrows point to the HAP/chitosan and WH/chitosan scaffold. (B, C) BMD and BV/TV in the defects implanted with the scaffolds. Mean \pm SD; $n=3$. *Significant difference between groups $(P<0.05)$.

Abbreviations: CT, computed tomography; WH, whitlockite; HAP, hydroxyapatite; hBMSCs, human mesenchymal stem cells; BMD, bone mineral density; BV/TV, bone volume to total bone volume.

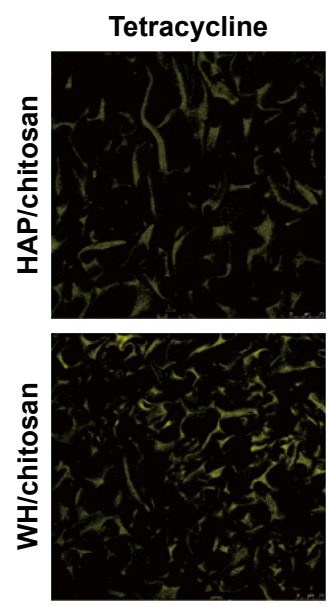

2 weeks
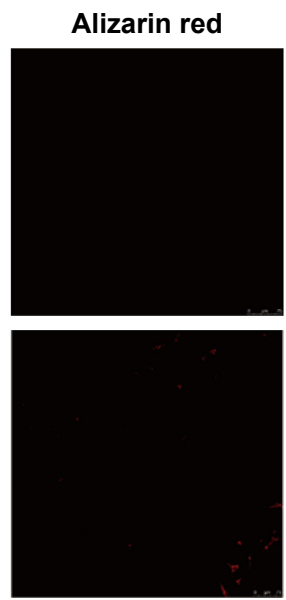

4 weeks
Calcein
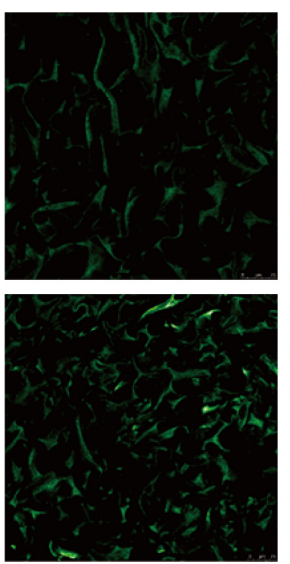

6 weeks
Merge
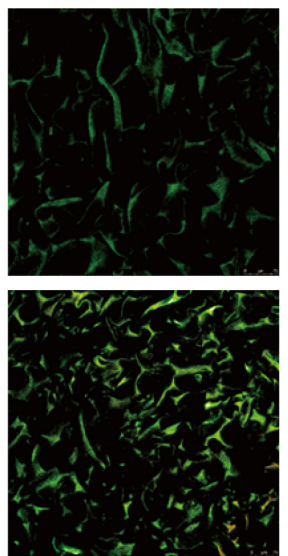

8 weeks
Van Gieson

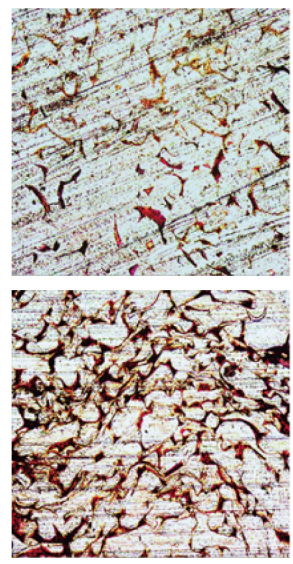

8 weeks

Figure I I New bone formation and mineralization measured histomorphometrically by fluorochrome-labeling analysis and Van Gieson's picrofuchsin in rat calvarial defects implanted with HAP/chitosan and WH/chitosan. Tetracycline (yellow), alizarin red (red), and calcein (green) were intraperitoneally injected at week 2, week 4, and week 6, respectively. Column 4 represents merged images of the three fluorochromes of the same sample and column 5 represents Van Gieson's picrofuchsin as a comparison. Abbreviations: $\mathrm{WH}$, whitlockite; HAP, hydroxyapatite. 

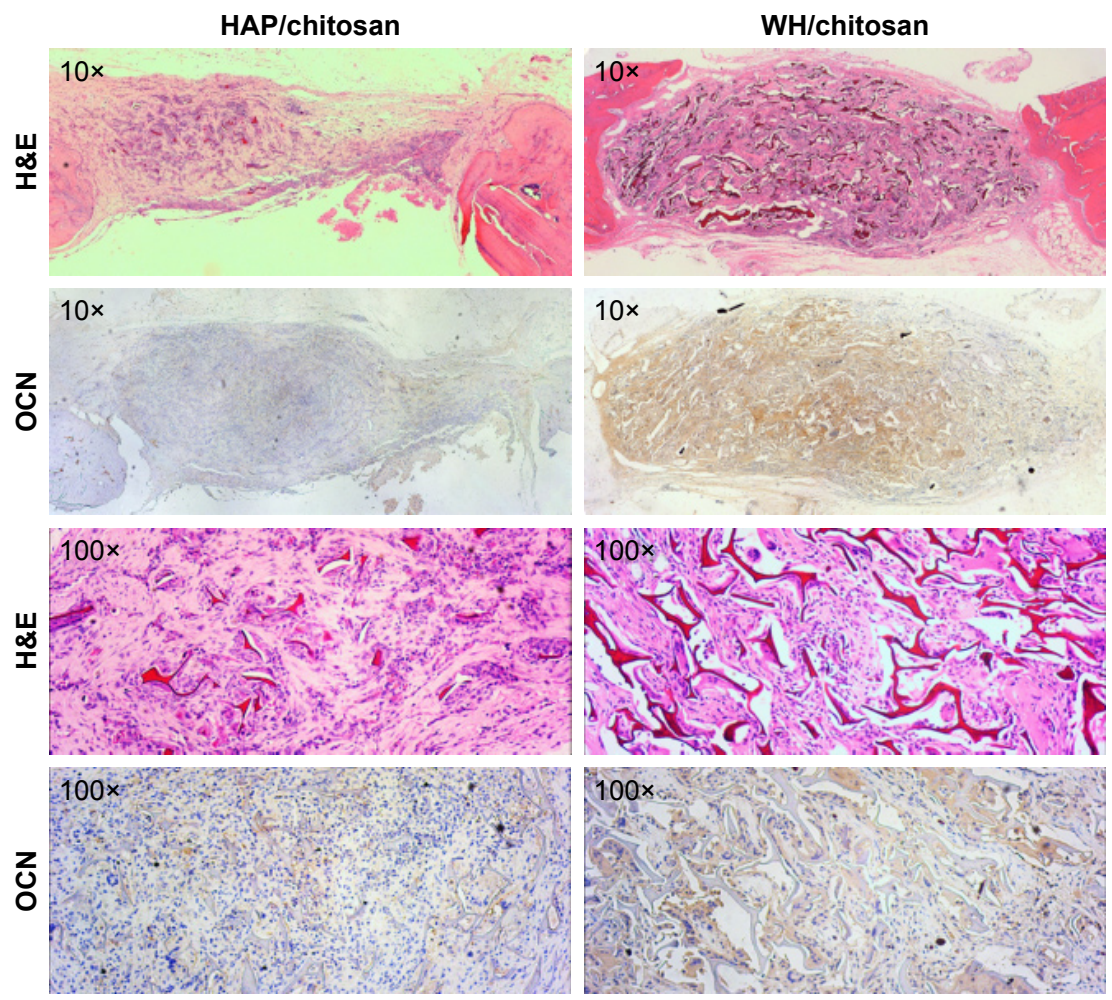

Figure $12 \mathrm{H \& E}$ staining and immunohistochemical staining of OCN in the defects implanted with HAP/chitosan and WH/chitosan scaffolds at 8 weeks post-implantation. A higher number of new bone were found in $\mathrm{WH} /$ chitosan. The OCN (stained brown) secreted from the new bone was also greater in $\mathrm{WH} / \mathrm{chitosan}$.

Abbreviations: WH, whitlockite; HAP, hydroxyapatite; H\&E, hematoxylin and eosin; OCN, osteocalcin.

osseous defect, we intend to test $\mathrm{WH} /$ chitosan in a manner of scaffold in repairing calvaria defects in rats.

In our study, WH/chitosan and HAP/chitosan membranes were used in vitro, as cells could be seeded on and harvested more conveniently. We found that $\mathrm{WH} /$ chitosan membrane promoted hBMSCs proliferation for 7 days and had no toxic effect on hBMSCs. Results also showed that $\mathrm{WH} /$ chitosan membrane significantly increased ALP activity compared to the HAP/chitosan group, as well as increased the osteogenic protein and gene expression levels compared to $\mathrm{HAP} /$ chitosan group, indicating that the $\mathrm{WH} /$ chitosan was capable of promoting osteogenic differentiation of hBMSCs.

In order to explore the potential clinical applications, an in vivo study on the ability of the scaffold to repair a criticalsized calvaria defect was performed. ${ }^{5,29}$ The critical-sized calvaria defect is described as an osseous defect of a particular diameter that leads to a failure in self-regeneration..$^{30,31}$ A full-thickness diameter of $5 \mathrm{~mm}$ is an ideal rat criticalsized calvaria defect model with no sign of spontaneous bone regeneration but fibrous tissue presentation, ${ }^{32}$ which is also confirmed by our study (data not shown). In our study, we mainly evaluated the ability of $\mathrm{WH} /$ chitosan and HAP/ chitosan scaffold in promoting bone formation. After 8 weeks postsurgery, the micro-CT images were analyzed with CTAn, a micro-CT processing program. Besides BV/TV, we also measured BMD parameter to analyze the strength of newly formed bone, as BMD refers to the density of minerals (such as calcium) in bone. ${ }^{33}$ The results of the present study showed that $\mathrm{WH} /$ chitosan scaffold significantly enhanced BV/TV and BMD at 8 weeks in comparison with the HAP/chitosan scaffolds. In general, new bone could spread on the surface of $\mathrm{WH} /$ chitosan and grow into the implants, presenting closer contact between new bones and implants themselves. By contrast, less numbers of newly formed bone tissue were found in HAP/chitosan group, with obvious vacancy between implants and preexisting bone. Moreover, in microscopic view, we found more bone ingrowth into the $\mathrm{WH} /$ chitosan scaffolds, with more positive area for fluorochrome labeling (for calcium deposition), Van Gieson (for collagen of newly formed bone), ${ }^{34}$ and $\mathrm{OCN}$ (for secreted protein from mature osteoblast $)^{35}$ staining.

We mainly attributed the better performance of bone regeneration of $\mathrm{WH} /$ chitosan to $\mathrm{Mg}$ incorporation, microstructure, and gradual release of $\mathrm{Ca}$ and $\mathrm{P}$ of the scaffolds. First, from ion release tests, we found sustained release of $\mathrm{Mg}$ from $\mathrm{WH} /$ chitosan in nearly a month. $\mathrm{Mg}$ is an essential trace element that is involved in many cellular enzymatic 
reactions and gene regulation through the modulation of several transcription factors. ${ }^{36,37}$ It can promote hBMSCs or osteogenic cell proliferation as well as osteogenic differentiation. ${ }^{38-40}$ In fact, $\mathrm{Mg}$ is found in natural enamel, dentine, and bone, and is associated with biologic apatite. Therefore, $\mathrm{Mg}$ is often incorporated into ceramics or adulterated into an alloy with other metal elements in order to promote osseous growth on implants. Magnesium alloys were reported to enhance bone formation in vivo as a loadbearing fixation devices and have been applied in medical use for over a century. ${ }^{41}$ Yamasaki et a ${ }^{42}$ incorporated $\mathrm{Mg}$ into carbonated apatite crystals which resulted in better adhesion of osteoblasts onto the composites and bone formation after being implanted beneath the periosteum cranii of rats. Hussain et a ${ }^{43}$ incorporated different concentrations of magnesium phosphate calcium (MCP) into gelatin sponges and prepared MCP gelatin scaffolds that could promote the healing of calvaria defects in rats. Additionally, Park et al ${ }^{44}$ prepared deproteinized porcine cancellous bone incorporated with $\mathrm{Mg}$ on the surface with which the rabbit calvaria defect could be better healed after implantation. Yoshizawa et $\mathrm{a}^{45}$ attributed these promoting effects to $\mathrm{Mg}$ incorporation with higher level of osteogenesis-related genes and mineralization when treating $\mathrm{hBMSCs}$ with $\mathrm{MgSO}_{4}$ at different concentrations. Landi et $\mathrm{al}^{46}$ reported that doping with low concentration of $\mathrm{Mg}$ and $\mathrm{MgCO}_{3}$ promoted the proliferation of mesenchymal stem cells and osteogenesis in early stages in comparison with HAP. In our study, the experimental results showed the enhanced proliferation, ALP activity, and osteogenesis-associated protein and genes in hBMSCs cultured on $\mathrm{WH} /$ chitosan in vitro and better ingrowth of new bone in $\mathrm{WH} /$ chitosan in vivo, and these results are consistent with the previous studies. In addition to $\mathrm{Mg}$ incorporation, the $\mathrm{WH} /$ chitosan scaffold exhibited porous structure with pore sizes of about $100 \mu \mathrm{m}$. The macropores allow the ingrowth of bone tissues to achieve better integration with the living bones ${ }^{47}$ Finally, owing to the lower rate of $\mathrm{P}$ and $\mathrm{Ca}$ degradation, the $\mathrm{WH} /$ chitosan scaffold is more durable for osteoblast adhesion and mineralization than $\mathrm{HAP} /$ chitosan.

Although WH/chitosan has been shown to be very useful in biomedical and tissue engineering, there still exist questions about the duration and dose of $\mathrm{Mg}$ released from $\mathrm{WH} /$ chitosan and in what style $\mathrm{WH} /$ chitosan exists in the long run. Accordingly, further studies are needed to monitor the change of serum $\mathrm{Mg}$ or the amount of $\mathrm{Mg}$ in peri-scaffold region after implanting $\mathrm{WH} /$ chitosan and its maintenance style in a longer period.

\section{Conclusion}

In summary, we have successfully synthesized porous $\mathrm{HAP} /$ chitosan and $\mathrm{WH} /$ chitosan scaffolds by freeze drying and comparatively investigated their effects on the bone regeneration in calvarial defects. Both the $\mathrm{HAP} /$ chitosan and $\mathrm{WH} /$ chitosan scaffolds possessed macropores with pore sizes of about $105 \mu \mathrm{m}$, which is beneficial to help the cells settle inside the scaffolds. The incorporation of $\mathrm{Mg}$ led to better bone formation in the $\mathrm{WH} /$ chitosan scaffold than in the HAP/chitosan scaffold. In vitro, the WH/chitosan membrane exhibited good biocompatibility, not only promoting the proliferation of hBMSCs but also improving osteoinductivity. The ALP activity, deposition of minerals, and osteogenesis-associated genes and protein of hBMSCs cultured on $\mathrm{WH} /$ chitosan are higher than those on HAP/ chitosan or the control. Moreover, the WH/chitosan scaffold significantly improved new bone formation in rat calvaria defects in comparison with the HAP/chitosan scaffold. Therefore, $\mathrm{WH} /$ chitosan scaffold is a promising candidate for bone defect repair.

\section{Acknowledgments}

Financial support from the National Natural Science Foundation of China (81272003), the Sixth People's Hospital of Shanghai Jiaotong University, and the Science and Technology Commission of Shanghai (15JC1491001) is gratefully acknowledged.

\section{Disclosure}

The authors declare no conflicts of interest in this work.

\section{References}

1. Gazdag AR, Lane JM, Glaser D, Forster RA. Alternatives to autogenous bone graft: efficacy and indications. J Am Acad Orthop Surg. 1995; $3(1): 1-8$.

2. Krause F, Younger A, Weber M. Recombinant human BMP-2 and allograft compared with autogenous bone graft for reconstruction of diaphyseal tibial fractures with cortical defects. J Bone Joint Surg Am. 2008; 90(5):1168-1169.

3. Wang C, Wang S, Li K, et al. Preparation of laponite bioceramics for potential bone tissue engineering applications. PLoS One. 2014;9(6): e99585.

4. Thorfve A, Lindahl C, Xia W, et al. Hydroxyapatite coating affects the Wnt signaling pathway during peri-implant healing in vivo. Acta Biomater. 2014;10(3):1451-1462.

5. Wang H, Zhao S, Xiao W, et al. Three-dimensional zinc incorporated borosilicate bioactive glass scaffolds for rodent critical-sized calvarial defects repair and regeneration. Colloids Surf B Biointerfaces. 2015;130: 149-156.

6. LeGeros RZ. Calcium phosphate-based osteoinductive materials. Chem Rev. 2008;108(11):4742-4753.

7. Palmer LC, Newcomb CJ, Kaltz SR, Spoerke ED, Stupp SI. Biomimetic systems for hydroxyapatite mineralization inspired by bone and enamel. Chem Rev. 2008;108:4754-4783. 
8. Guo YP, Guan JJ, Yang J, Wang Y, Zhang CQ, Ke QF. Hybrid nanostructured hydroxyapatite-chitosan composite scaffold: bioinspired fabrication, mechanical properties and biological properties. J Mater Chem B. 2015;3(23):4679-4689.

9. Zhang H, Fu QW, Sun TW, et al. Amorphous calcium phosphate, hydroxyapatite and poly(d,1-lactic acid) composite nanofibers: electrospinning preparation, mineralization and in vivo bone defect repair. Colloids Surf B Biointerfaces. 2015;136:27-36.

10. Bhumiratana S, Grayson WL, Castaneda A, et al. Nucleation and growth of mineralized bone matrix on silk-hydroxyapatite composite scaffolds. Biomaterials. 2011;32(11):2812-2820.

11. Jang HL, Jin K, Lee J, et al. Revisiting whitlockite, the second most abundant biomineral in bone: nanocrystal synthesis in physiologically relevant conditions and biocompatibility evaluation. ACS Nano. 2014; 8(1):634-641.

12. Qi C, Zhu YJ, Chen F, Wu J. Porous microspheres of magnesium whitlockite and amorphous calcium magnesium phosphate: microwaveassisted rapid synthesis using creatine phosphate, and application in drug delivery. J Mater Chem B. 2015;3(39):7775-7786.

13. Qi C, Chen F, Wu J, Zhu YJ, Hao CN, Duan JL. Magnesium whitlockite hollow microspheres: a comparison of microwave-hydrothermal and conventional hydrothermal syntheses using fructose 1,6-bisphosphate, and application in protein adsorption. RSC Adv. 2016;6(40):33393-33402.

14. Jang HL, Zheng GB, Park J, et al. In vitro and in vivo evaluation of whitlockite biocompatibility: comparative study with hydroxyapatite and $\beta$-tricalcium phosphate. Adv Healthc Mater. 2016;5(1):128-136.

15. Toskas G, Cherif C, Hund RD, et al. Chitosan(PEO)/silica hybrid nanofibers as a potential biomaterial for bone regeneration. Carbohydr Polym. 2013;94(2):713-722.

16. Tanase CE, Popa MI, Verestiuc L. Biomimetic chitosan-calcium phosphate composites with potential applications as bone substitutes: preparation and characterization. J Biomed Mater Res B Appl Biomater. 2012;100(3):700-708.

17. Meng D, Dong L, Wen Y, Xie Q. Effects of adding resorbable chitosan microspheres to calcium phosphate cements for bone regeneration. Mater Sci Eng C Mater Biol Appl. 2015;47:266-272.

18. Zhang X, Zhu L, Lv H, et al. Repair of rabbit femoral condyle bone defects with injectable nanohydroxyapatite/chitosan composites. J Mater Sci Mater Med. 2012;23(8):1941-1949.

19. Sahin YM, Yetmez M, Oktar FN, et al. Nanostructured biomaterials with antimicrobial properties. Curr Med Chem. 2014;21(29):3391-3404.

20. Qi C, Zhu YJ, Lu BQ, et al. Hydroxyapatite hierarchically nanostructured porous hollow microspheres: rapid, sustainable microwavehydrothermal synthesis by using creatine phosphate as an organic phosphorus source and application in drug delivery and protein adsorption. Chem Eur J. 2013;19(17):5332-5341.

21. van Gaalen SM, Kruyt MC, Geuze RE, de Bruijn JD, Alblas J, Dhert WJ. Use of fluorochrome labels in in vivo bone tissue engineering research. Tissue Eng Part B Rev. 2010;16(2):209-217.

22. Marques C, Ferreira JM, Andronescu E, Ficai D, Sonmez M, Ficai A. Multifunctional materials for bone cancer treatment. Int J Nanomedicine. 2014;9:2713-2725.

23. Komori T, Yagi H, Nomura $\mathrm{S}$, et al. Targeted disruption of Cbfa1 results in a complete lack of bone formation owing to maturational arrest of osteoblasts. Cell. 1997;89(5):755-764.

24. Bruderer M, Richards RG, Alini M, Stoddart MJ. Role and regulation of RUNX2 in osteogenesis. Eur Cell Mater. 2014;28:269-286.

25. Im GI, Qureshi SA, Kenney J, Rubash HE, Shanbhag AS. Osteoblast proliferation and maturation by bisphosphonates. Biomaterials. 2004; 25(18):4105-4115.

26. Dong J, Kojima H, Uemura T, Kikuchi M, Tateishi T, Tanaka J. In vivo evaluation of a novel porous hydroxyapatite to sustain osteogenesis of transplanted bone marrow-derived osteoblastic cells. J Biomed Mater Res. 2001;57(2):208-216.

27. Lagier R, Baud CA. Magnesium whitlockite, a calcium phosphate crystal of special interest in pathology. Pathol Res Pract. 2003;199(5): 329-335.
28. Jang HL, Jin K, Lee J, et al. Revisiting whitlockite, the second most abundant biomineral in bone: nanocrystal synthesis in physiologically relevant conditions and biocompatibility evaluation. ACS Nano. 2013;8(1):634-641.

29. Zhao S, Wang H, Zhang Y, et al. Copper-doped borosilicate bioactive glass scaffolds with improved angiogenic and osteogenic capacity for repairing osseous defects. Acta Biomater. 2015;14:185-196.

30. Schmitz JP, Hollinger JO. The critical size defect as an experimental model for craniomandibulofacial nonunions. Clin Orthop Relat Res. 1986;205:299-308.

31. Blanquaert F, Saffar JL, Colombier ML, Carpentier G, Barritault D, Caruelle JP. Heparan-like molecules induce the repair of skull defects. Bone. 1995;17(6):499-506.

32. Bosch C, Melsen B, Vargervik K. Importance of the critical-size bone defect in testing bone-regenerating materials. J Craniofac Surg. 1998; 9(4):310-316.

33. Kim YJ, Henkin J. Micro-computed tomography assessment of human alveolar bone: bone density and three-dimensional micro-architecture. Clin Implant Dent Relat Res. 2015;17(2):307-313.

34. Prentø P. Van Gieson's picrofuchsin. The staining mechanisms for collagen and cytoplasm, and an examination of the dye diffusion rate model of differential staining. Histochemistry. 1993;99(2):163-174.

35. Hasegawa T, Oizumi K, Yoshiko Y, Tanne K, Maeda N, Aubin JE. The PPARgamma-selective ligand BRL-49653 differentially regulates the fate choices of rat calvaria versus rat bone marrow stromal cell populations. BMC Dev Biol. 2008;8:71.

36. Miao EA, Freeman JA, Miller SI. Transcription of the SsrAB regulon is repressed by alkaline $\mathrm{pH}$ and is independent of PhoPQ and magnesium concentration. J Bacteriol. 2002;184(5):1493-1497.

37. Yuguan Z, Min Z, Luyang L, et al. Effects of cerium on key enzymes of carbon assimilation of spinach under magnesium deficiency. Biol Trace Elem Res. 2009;131(2):154-164.

38. Yang C, Yuan G, Zhang J, Tang Z, Zhang X, Dai K. Effects of magnesium alloys extracts on adult human bone marrow-derived stromal cell viability and osteogenic differentiation. Biomed Mater. 2010;5(4): 045005 .

39. Chai $\mathrm{H}$, Guo $\mathrm{L}$, Wang $\mathrm{X}$, et al. In vitro and in vivo evaluations on osteogenesis and biodegradability of a $\beta$-tricalcium phosphate coated magnesium alloy. J Biomed Mater Res A. 2012;100(2):293-304.

40. Zhao SF, Jiang QH, Peel S, Wang XX, He FM. Effects of magnesiumsubstituted nanohydroxyapatite coating on implant osseointegration. Clin Oral Implants Res. 2013;24 Suppl A100:34-41.

41. Witte F. Reprint of: the history of biodegradable magnesium implants: a review. Acta Biomater. 2015;23 Suppl:S28-S40.

42. Yamasaki Y, Yoshida Y, Okazaki M, et al. Action of FGMgCO3Apcollagen composite in promoting bone formation. Biomaterials. 2003; 24(27):4913-4920.

43. Hussain A, Takahashi K, Sonobe J, Tabata Y, Bessho K. Bone regeneration of rat calvarial defect by magnesium calcium phosphate gelatin scaffolds with or without bone morphogenetic protein-2. J Maxillofac Oral Surg. 2014;13(1):29-35.

44. Park JW, Ko HJ, Jang JH, Kang H, Suh JY. Increased new bone formation with a surface magnesium-incorporated deproteinized porcine bone substitute in rabbit calvarial defects. J Biomed Mater Res A. 2012; 100(4):834-840.

45. Yoshizawa S, Brown A, Barchowsky A, Sfeir C. Magnesium ion stimulation of bone marrow stromal cells enhances osteogenic activity, simulating the effect of magnesium alloy degradation. Acta Biomater. 2014; 10(6):2834-2842.

46. Landi E, Tampieri A, Mattioli-Belmonte M, et al. Biomimetic Mgand $\mathrm{Mg}, \mathrm{CO} 3$-substituted hydroxyapatites: synthesis characterization and in vitro behaviour. J Eur Ceram Soc. 2006;26(13):2593-2601.

47. Karageorgiou V, Kaplan D. Porosity of 3D biomaterial scaffolds and osteogenesis. Biomaterials. 2005;26(27):5474-5491. 
International Journal of Nanomedicine

Dovepress

\section{Publish your work in this journal}

The International Journal of Nanomedicine is an international, peerreviewed journal focusing on the application of nanotechnology in diagnostics, therapeutics, and drug delivery systems throughout the biomedical field. This journal is indexed on PubMed Central, MedLine, CAS, SciSearch ${ }^{\circledR}$, Current Contents ${ }^{\circledR} /$ Clinical Medicine,
Journal Citation Reports/Science Edition, EMBase, Scopus and the Elsevier Bibliographic databases. The manuscript management system is completely online and includes a very quick and fair peer-review system, which is all easy to use. Visit http://www.dovepress.com/ testimonials.php to read real quotes from published authors.

Submit your manuscript here: http://www.dovepress.com/international-journal-of-nanomedicine-journal 